\title{
Multiple Axonal Spike Initiation Zones in a Motor Neuron: Serotonin Activation
}

\author{
Pierre Meyrand, ${ }^{1}$ James M. Weimann, ${ }^{2}$ and Eve Marder ${ }^{2}$ \\ 'Laboratoire de Neurobiologie Comparée, CNRS and Université de Bordeaux, Arcachon, France 33210 and ${ }^{2}$ Biology \\ Department, Brandeis University, Waltham, Massachusetts 02254
}

The lateral gastric (LG) motor neuron of the stomatogastric nervous system of the crab Cancer borealis has a large soma in the stomatogastric ganglion (STG). The LG motor neuron makes inhibitory synaptic connections within the neuropil of the STG, and also projects to the periphery, where it innervates a series of muscles that control the movements of the lateral teeth of the gastric mill. The LG motor neuron has a spike initiation zone close to its neuropilar integrative regions, from which spikes propagate orthodromically to the muscles. Additionally, under certain conditions, the LG neuron can initiate spikes at peripheral axonal sites that can be $0.5-$ $2.0 \mathrm{~cm}$ from the STG. Peripherally initiated spikes propagate antidromically into the STG and also propagate to the muscle. The peripheral spike initiation zones are often active in combined preparations in which the muscles are left attached. When the muscles are removed, depolarization of the LG soma together with 5-HT applied to the motor nerve also evokes peripheral spike initiation. At a given 5-HT concentration, the duration of the trains of antidromic spikes can be controlled by current injection into the soma, suggesting the presence of a slow voltage-dependent conductance in the LG axon. The antidromic spikes contribute to lengthening of the duration of contraction in some of the muscles innervated by the LG, but do not evoke IPSPs onto LG follower neurons. Thus, the LG neuron can send different signals to its peripheral and central targets.

Neurons can show remarkably complex structures that have important consequences for signal processing. In many vertebrate and invertebrate neurons, action potentials are generated in one location, usually the axon hillock (see Tauc, 1962; Smith et al., 1982). However, some neurons possess multiple sites for action potential generation. In particular, there are neurons that project between ganglia that can initiate action potentials in several ganglia, in response to local synaptic inputs (e.g., Vedel and Moulins, 1978; Calabrese, 1980; Dickinson et al., 1981; Nagy et al., 1981).

When neurons initiate spikes at multiple loci, it is important to determine the trajectories by which the spikes travel from each site of initiation. For example, it is possible that spikes

\footnotetext{
Received Sept. 18, 1991; reviewed Feb. 12, 1992; accepted Feb. 20, 1992

We are grateful to Mr. M. O'Neil for the help with figure preparation. This work was supported by NIH Grant NS17813, NATO Travel Award 0540/86, and the Human Frontier Science Program.

Correspondence should be addressed to Dr. Eve Marder, Biology Department, Brandeis University, Waltham, MA 02254.

Copyright (C) 1992 Society for Neuroscience $0270-6474 / 92 / 122803-10 \$ 05.00 / 0$
}

initiated at some sites of a complex neuron may propagate through the entire neuron, whereas spikes initiated at other sites may not do so. In the latter case, it becomes important to determine, for each site of spike initiation, the physiological sequelae that result. Indeed, Mulloney and Selverston (1972) showed that antidromically activated action potentials in the lateral pyloric neuron of the stomatogastric ganglion (STG) fail to elicit IPSPs in the pyloric dilator neuron, while orthodromically activated action potentials are effective. In this article we again show that antidromic and orthodromic spikes do not evoke. the same postsynaptic actions.

Although it is now clear that neurons have many different voltage- and time-dependent conductances that confer on them their individual electrical properties, it is generally thought that axons have fewer types of conductances than somata and neuropilar processes. In fact, it is usually assumed that most axons generate action potentials using voltage-dependent conductances similar to those described by Hodgkin and Huxley (1952) for the squid axon. However, it is clear that at least one other type of current, the A current, is important for the control of the firing frequency in axons (Connor et al., 1977). Despite this, the presumption is that it is unlikely that other voltage-dependent currents are found on most axons. One of the interesting possibilities suggested by the work presented in this article is that some regions of axons may display slow voltage-dependent currents that can modulate the axonal membrane.

There is a large body of literature showing that presynaptic terminals of neurons, including many motor neurons, possess receptors to many neurotransmitters and neuromodulators. In particular, one of the first reports of neuromodulation was the finding that 5-HT can modulate synaptic release (Dudel, 1965) and elicit spontaneous nerve terminal activity (Grundfest and Reuben, 1961) at some crustacean neuromuscular junctions. Although nerve terminals are often chemosensitive, it is generally assumed that motor nerves are not sensitive to neurotransmitters or circulating hormones. Here we present data that indicate that the motor nerve containing the axon of the lateral gastric (LG) neuron is sensitive to 5-HT.

There are reports of peripheral action potential generation close to the terminals of motor neurons (Standaert, 1963, 1964). Moreover, Maranto and Calabrese (1984) showed that HE motor neurons in the leech heart system can burst and fire antidromic spikes from a peripheral plexus zone, and that this peripheral activity may function to ensure rhythmic heart tube activity. We demonstrate that the peripheral axon of the LG motor neuron can generate action potentials in combined preparations and provide a possible behavioral role for this phenomenon. 


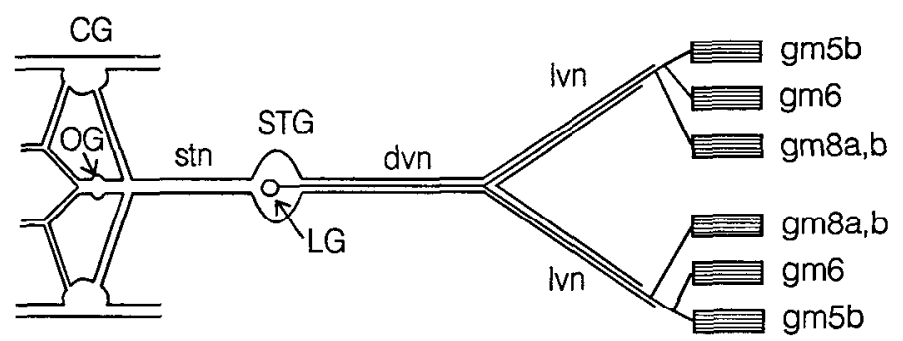

Figure 1. Schematic diagram of the dissected stomatogastric nervous system of $C$. borealis including the gastric mill muscles. $C G$, commissural ganglion; $O G$, esophageal ganglion; $S T G$, stomatogastric ganglion; $s t n$, stomatogastric nerve; $d v n$, dorsal ventricular nerve; $l v n$, lateral ventricular nerve; $L G$, lateral gastric motor neuron; $g m 5 b, g m 6, g m 8 a, b$, the three bilateral gastric muscle groups innervated by the LG neuron.

In this article we have studied properties of the LG neuron of the crab STG. The LG neuron innervates a set of bilaterally symmetrical muscles that close the lateral teeth of the gastric mill. The gastric mill of lobsters and crabs is involved in the maceration of ingested strips of food into smaller particles, which are then processed by the pyloric filter apparatus before passing into the midgut. The LG, as well as the other STG motor neurons, is an important component of the networks that control the motor patterns generated by the STG. Therefore, processes that shape the activity of the LG have implications for movement (because the LG is a motor neuron) and for pattern generation (because the LG neuron synapses directly on many of the other pattern-generating elements of the STG).

\section{Materials and Methods}

Cancer borealis were purchased from local (Boston, MA) fishermen and kept in aerated aquaria at $12^{\circ} \mathrm{C}$. Seventy-five animals weighing between 300 and $600 \mathrm{gm}$ were used.

All experiments reported in this article were repeated at least three times. A complete description of the dissections and techniques employed can be found in Selverston and Moulins (1987). The combined nerve-muscle preparation used in most of these experiments is described in Hooper et al. (1986) and Weimann et al. (1991). Briefly, the stomach was removed from the animal and slit ventrally from the esophagus to the midgut. The stomach was then pinned flat in a dissecting dish, and the anterior ganglia, STG, and associated nerves were detached from the anterior stomach wall and muscles while the posterior gastric and pyloric muscles remained innervated. This combined preparation was transferred and pinned to a Sylgard-coated Petri dish. A schematic diagram is illustrated in Figure 1. After desheathing the stomatogastric ganglion (STG) and stomatogastric nerve (stn), stainless steel monopolar extracellular recording electrodes were placed on the nerves. A Vaseline well around the desheathed portion of the stn allowed us to put an isotonic sucrose $(750 \mathrm{~mm})$ solution into this well to block the stn. In all figure diagrams where "sucrose" points to a circle, this indicates that impulse conduction via the nerve was blocked. A double superfusion system and a Vaseline well around the motor nerves were used so that serotonin (5-HT; Sigma) could be superfused over the motor nerves while the muscles and STG were superfused with normal saline.

Physiological saline had the following composition: $\mathrm{NaCl}, 440 \mathrm{~mm}$; $\mathrm{KCl}, 11.3 \mathrm{~mm} ; \mathrm{CaCl}_{2}, 13.3 \mathrm{~mm} ; \mathrm{MgCl}_{2}, 26.3 \mathrm{~mm}$; Trizma base, 11.0 $\mathrm{mm}$; maleic acid, $5.2 \mathrm{mM}, \mathrm{pH}, 7.4-7.5$. Saline, cooled to $12-13^{\circ} \mathrm{C}$, was superfused at a rate of $10-25 \mathrm{ml} / \mathrm{min}$ into both chambers.

Glass micropipettes filled with 4 м K-acetate ( $20-40 \mathrm{M} \Omega$ resistance) were used for both neuron and muscle recordings. Membrane potential control of the LG neuron was achieved with two-electrode current clamp using two Getting $5 \mathrm{~A}$ amplifiers. Muscle movements were recorded with a force/displacement transducer built by M. O'Neil (Brandeis University) (details in Meyrand and Marder, 1991).

A

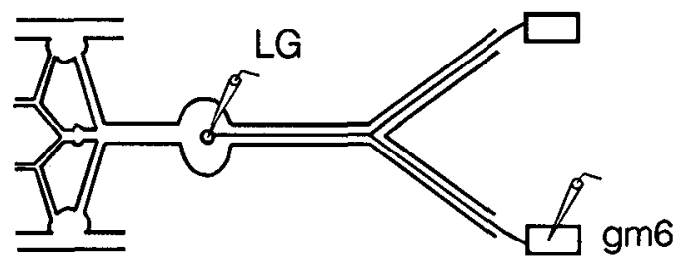

B

LG
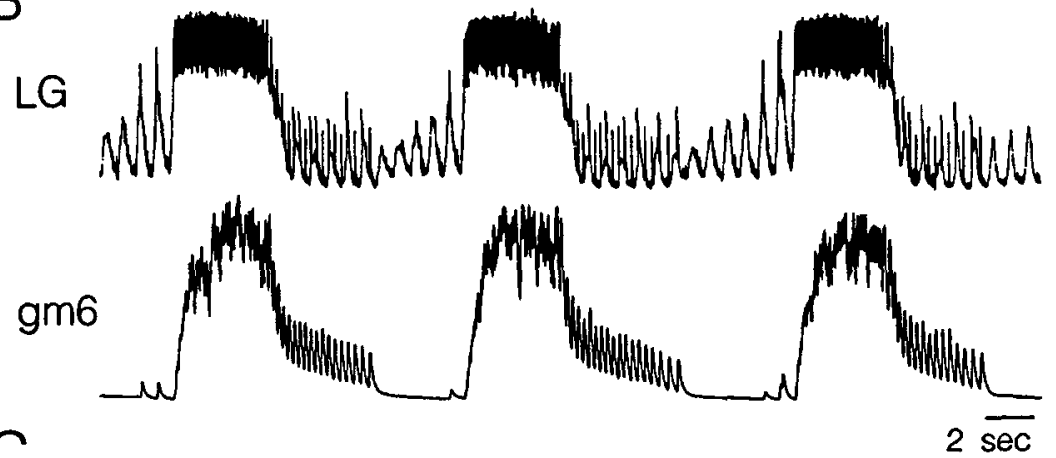

Figure 2. Spontaneous gastric activity of $L G$ neuron with gastric muscles still attached as seen in schematic in $A . B$, Simultaneous intracellular recordings of LG motor neuron and a gm6 muscle fiber. $C$, Same recordings but with time base expanded. Hatched bar, action potentials due to LG depolarization; open bar, action potentials occurring below spike threshold of $-45 \mathrm{mV}$. Most hyperpolarized potential of $\mathrm{LG},-65 \mathrm{mV}$.

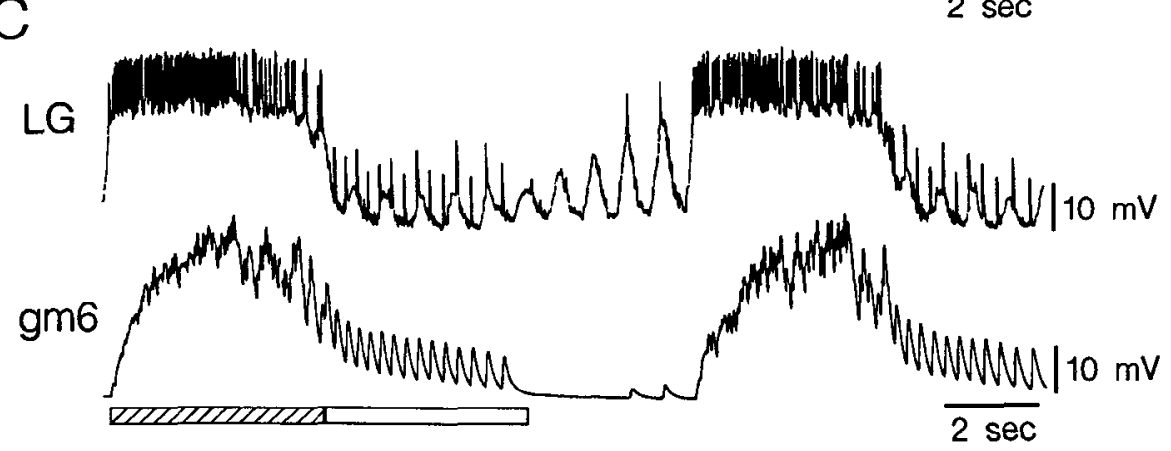




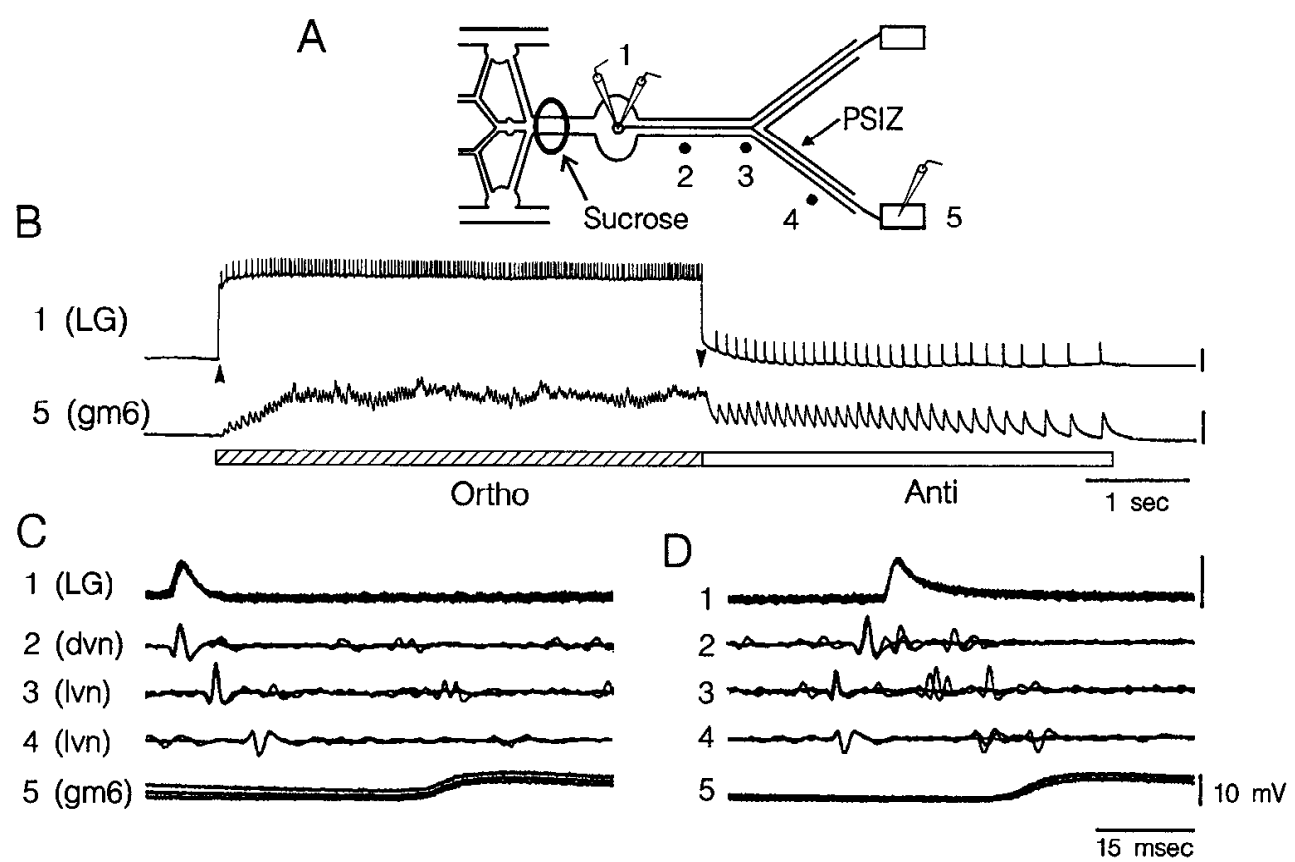

Figure 3. A, Schematic diagram of combined preparation with sucrose block on stn. LG is impaled with current-injecting and recording electrodes. Three extracellular electrodes are placed on the motor nerves, and another intracellular electrode records EJPs in the gm6 muscle. PSIZ, peripheral spike interaction zone. $B$, Intracellular recordings of LG and gm6 muscle during LG depolarization to - $30 \mathrm{mV}$ (arrow) produced orthodromic spikes (hatched bar). When the potential is returned to $-65 \mathrm{mV}$, only antidromic spikes are seen (open bar). $C$, Three superimposed sweeps triggered by LG action potential in lvn. Orthodromic spikes were generated from a smaller depolarization, so the spike frequency was lower. The spikes originate between the soma and extracellular electrode on the dvn (2) and then travel to electrodes 3 and 4 on lvn and finally produce EJP at the muscle. $D$, Three superimposed sweeps triggered on spikes after the depolarization. Spikes originate in the lvn between electrodes 3 and 4 and propagate antidromically toward the soma.

Data were recorded on a Tektronix oscilloscope, a Gould ES1000 electrostatic recorder, a Gould 440 pen recorder, and a Vetter tape recorder. Multiple sweep analysis was performed with R.C. Electronic Computerscope software on an $386 / 25 \mathrm{MHz}$ IBM PC.

\section{Results}

\section{Spontaneous peripheral spike initiation}

In combined preparations, consisting of the stomatogastric nervous system and the gastric mill and pyloric muscles, the gastric rhythm was often spontaneously active. Under these conditions, recordings from the LG motor neuron showed action potentials riding on the top of the slow depolarization of the LG neuron during its active phase of the gastric cycle. In these preparations with muscles attached and contracting, the LG neuron also fired extra action potentials during its hyperpolarized phase (Fig. 2). Figure $2 B$ shows simultaneous intracellular recordings from the LG motor neuron and a fiber of the gm6 muscle (one of the muscles innervated by the LG), and expanded time base recordings are seen in Figure $2 C$. During spontaneous gastric activity, LG depolarized and produced a burst of action potentials about every $15 \mathrm{sec}$. Each LG action potential elicited an excitatory junctional potential (EJP) in the gm 6 muscle (lower traces). After the LG burst, lower-frequency spikes were observed for several seconds during the hyperpolarized $(-65 \mathrm{mV})$ phase of the I G oscillation.

The spikes that occurred from a hyperpolarized baseline membrane potential were puzzling because the threshold for normal spike initiation during gastric bursts was around -45 $\mathrm{mV}$ (as measured in the soma), as seen by the two spikes prior to the second burst in Figure $2 C$. This suggested the possibility that the action potentials that trail the burst might have been initiated at a different location, more distant from the soma than the spikes that ride on top of the depolarizing waves during gastric activity.

To localize the site of spike initiation, we placed two electrodes into the LG soma, three extracellular electrodes along the nerves leading to the muscles that LG innervates, and an electrode in a fiber of one of the gm6 muscles (Fig. $3 A$ ). Impulse conduction in the descending CNS input fibers in the stn was blocked using a sucrose well so that the rhythmic activity in the STG was suppressed. The LG was depolarized several times from resting potential $(-65 \mathrm{mV})$ to a potential normally seen during gastric activity $(-30$ to $-40 \mathrm{mV}$ ) for $5 \mathrm{sec}$, and the recordings shown in Figure $3 B$ were from the fifth such depolarization. The action potentials that occur during a depolarization are orthodromic (Fig. 3C) since they are recorded first in the soma and then travel away from the soma toward the muscle. Subsequent to the $5 \mathrm{sec}$ depolarization, action potentials were seen, although the membrane potential was once again hyperpolarized (Fig. 3B). These action potentials were first seen on electrode 3 (an extracellular electrode on the nerve), and then these spikes propagated into the soma and toward the muscle (Fig. 3D). Thus, from the vantage point of the soma, these are antidromic action potentials. When the muscles are attached but inputs from the CNS are blocked (as in Fig. 3), antidromic action potentials are often not seen after the first depolarization but appear after several depolarizations applied in succession. In somatic recordings the orthodromic action potentials are smaller than the antidromic action potentials and have a small afterhyperpolarization (Fig. 3). Repolarization of the antidromic action potentials does not appear to be active as they decay slowly back to resting potential. This is likely to occur because 


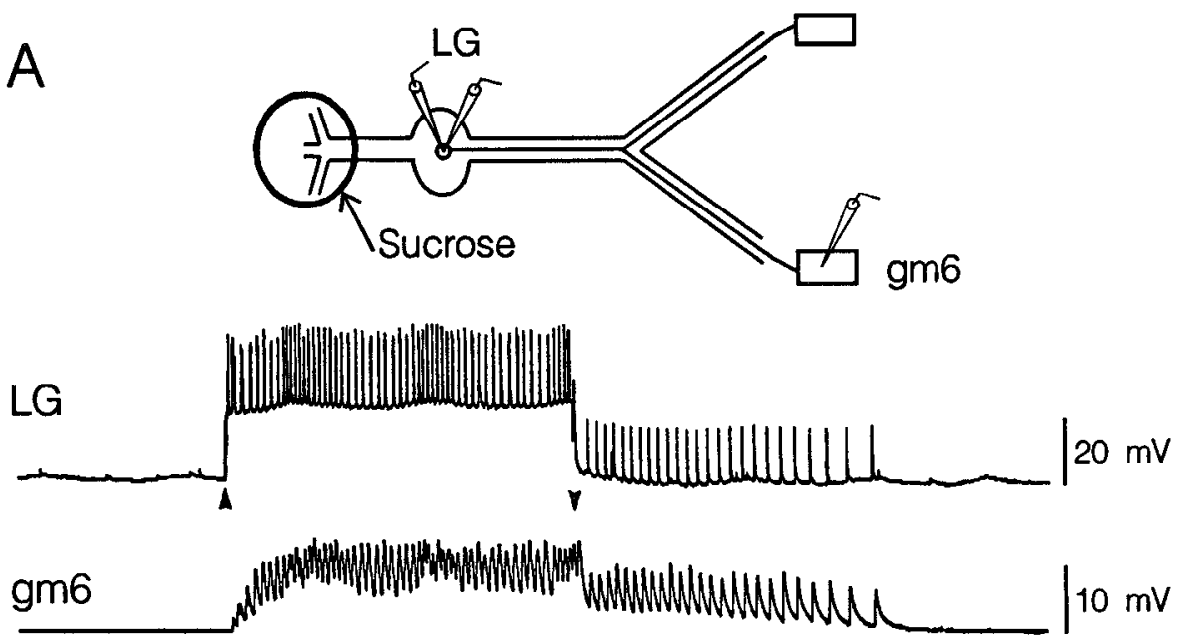

Figure 4. When gastric mill muscles are attached, the peripheral spike initiation zone is spontaneously expressed. $A$, Simultaneous intracellular records of the LG neuron and gm6 muscle. $\mathrm{LG}$ is depolarized to $-40 \mathrm{mV}$ from $-58 \mathrm{mV}$ between the arrowheads, producing EJPs in the muscle (resting potential, $-62 \mathrm{mV}$ ), and triggering the antidromic spikes. $B$, Muscles were removed, and several hours later depolarization from $-60 \mathrm{mV}$ to $-32 \mathrm{mV}$ did not elicit antidromic spikes.
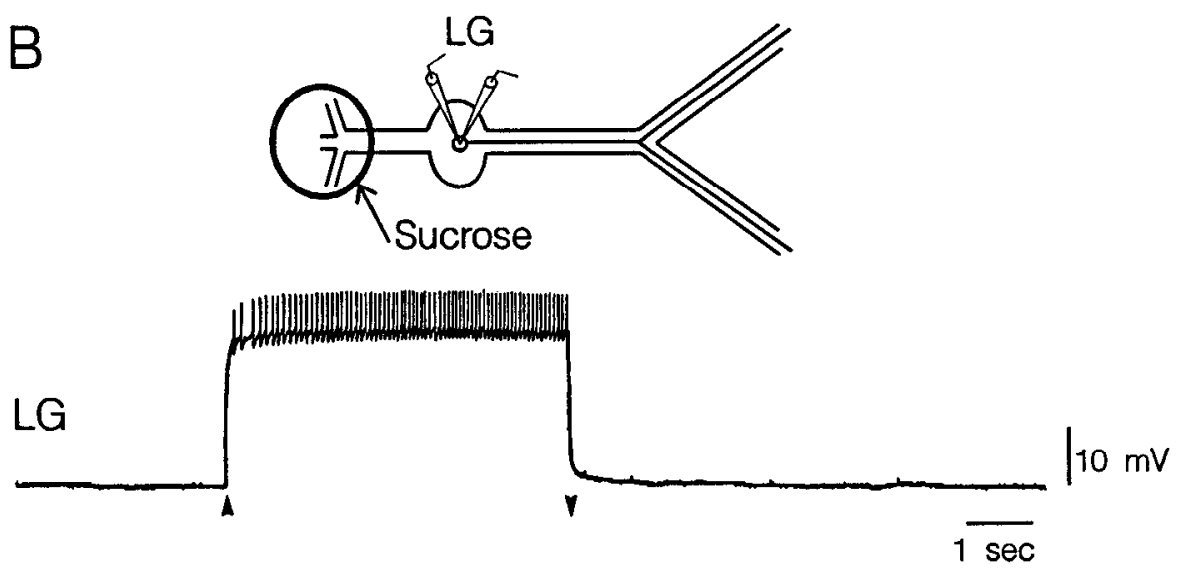

the two outward currents that participate in spike repolarization do not activate in crab STG neurons at voltages more hyperpolarized than $-40 \mathrm{mV}$ (Golowasch and Marder, 1992).

\section{Control of axonal spike initiation}

The activity of the axonal spike initiation zone is dependent upon the presence of the gastric mill muscles. In all experiments in which spontaneous axonal spikes were observed, the gastric mill muscles were attached and contracting. Figure $4 A$ illustrates an expcrimcnt in which the STG and gastric muscles were intact and the LG neuron was depolarized with $5 \mathrm{sec}$ pulses several times. This paradigm elicited antidromic spikes in the LG axon. However, several hours after the muscles were removed, antidromic spikes (Fig. $4 B$ ) were no longer evoked by repetitive depolarizations. We hypothesized that the muscle contractions evoked by the LG might excite a pair of sensory neurons known to contain 5-HT, the gastropyloric receptor (GPR) neurons (Belt $\angle$ et al., 1984; Katz et al., 1989), and that excitation of these neurons might explain the requirement for the presence of the muscles for the expression of peripheral spiking. Moreover, 5HT-like-immunoreactive punctate processes are found in the part of the lateral ventricular nerve (lvn) that shows peripheral spiking (V. Kilman and E. Marder, unpublished observations). Therefore, we were curious to determine whether 5-HT, applied to the portion of the motor nerve where the peripheral spike initiation zone is located, but not to the STG itself, could substitute for the presence of the muscles.
Figure 5 shows that in the absence of attached muscles, antidromic action potentials were easily evoked when low concentrations of 5-HT were applied to the nerve and the I Gr soma was depolarized. In the experiment shown in Figure 5, the STG was isolated from descending input by placing a sucrose well around the stn, and another well was made around the peripheral nerves [dorsal ventricular nerve (dvn)/lvn]. As a control, saline was placed in the well surrounding the nerves and LG was depolarized several times for a duration of $5 \mathrm{sec}$; no axonal spikes were observed. One minute after replacing the control saline with saline containing $10^{-7} \mathrm{M} 5-\mathrm{HT}$, the depolarization activated the axonal spike initiation zone (Fig. $5 B$ ).

All preparations showed the same sequence of events (see below) as 5-HT concentrations were increased. However, the absolute concentrations at which any phenomenon was observed (e.g., threshold for antidromic activity) varied by about an order of magnitude in different preparations. For example, antidromic activity was sometimes seen at concentrations as low as $10^{-8} \mathrm{M}$, but more commonly $10^{-7} \mathrm{M}$ 5-HT was required.

In the presence of a given 5-HT concentration, the duration of the depolarization of the LG soma is critically important in regulating the axonal spike initiation zone. During gastric activity, the LG neuron will depolarize in bursts that are several seconds long. In medium 5-HT concentrations $\left(10^{-6} \mathrm{M}\right.$ or lower), short depolarizations of the $\mathrm{LG}$ failed to induce antidromic spikes $(n=8)$, but long depolarizations did so (Fig. 6). In the experiment shown in Figure 6, the peripheral nerves were bathed 


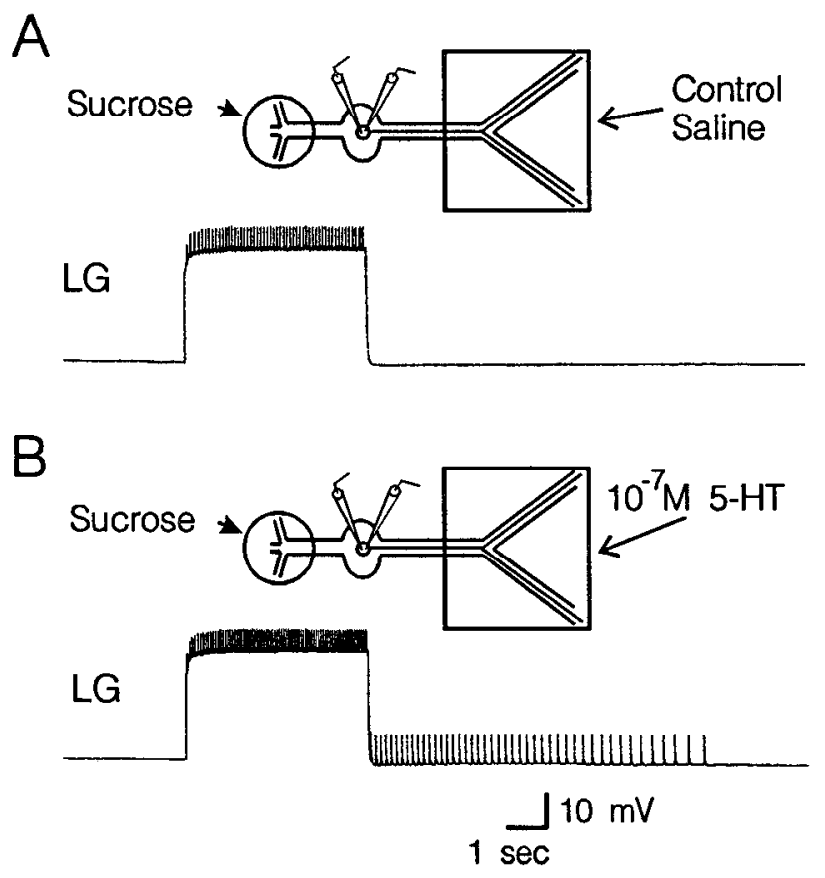

Figure 5. Expression of peripheral spikes is 5-HT dependent. $A$, Depolarizing $\mathrm{LG}$ to $-30 \mathrm{mV}$ from $-63 \mathrm{mV}$ for $5 \mathrm{sec}$ without the muscles attached does not produce antidromic action potentials. $B$, If $10^{-7} \mathrm{M}$ 5-HT is superfused only over the descending motor nerves, the peripheral spike initiation zone is revealed.

in $10^{-6} \mathrm{M} 5-\mathrm{HT}$ and the LG soma was depolarized from -53 $\mathrm{mV}$ to $-30 \mathrm{mV}$ for $1-5 \mathrm{sec}$. Depolarizations of 1 or $2 \mathrm{sec}$ did not elicit antidromic spikes, but depolarizing the soma for $3 \mathrm{sec}$ or longer did so. The number of antidromic spikes increased as the stimulus duration increased from 3 to $5 \mathrm{sec}$ (Fig. 6). The duration and spike frequency of the axonal burst of action potentials were proportional to the amount of current injected into the LG soma. At higher 5-HT concentrations, shorter-duration depolarizations were sufficient to evoke antidromic action potentials, and at high concentrations $\left(>1-5 \times 10^{-6} \mathrm{M}\right)$ a single orthodromic or antidromic action potential could elicit minutes of activity in the peripheral spike initiation zone. The dose dependence of the continuous firing of the peripheral zone was variable among animals; it varied between $5 \times 10^{-5} \mathrm{M}$ and $10^{-6} \mathrm{M}$.

Although the peripheral spike initiation zone can be several centimeters from the LG soma, current injected into the soma profoundly influences its activity. In the experiment shown in Figure $7 A$ the preparation was placed in $10^{-6} \mathrm{M} 5$-HT. Under these conditions, a single stimulus was sufficient to elicit long, continuous trains of axonally initiated spikes. Hyperpolarization of the soma to $-100 \mathrm{mV}$ for $5 \mathrm{sec}$ during this time abolished the axonal spikes. Upon release of negative current, the neuron rebounded and resumed firing antidromic action potentials (Fig. $7 A$ ). In the same type of experiment as described above but with the current injection electrode in the soma and the voltage recording electrode in the major neurite of the LG neuron, manipulation of the membrane potential altered the firing frequency of the axonal spikes (Fig. $7 B$ ). When the soma was depolarized such that the membrane potential of the neurite shifted from $-59 \mathrm{mV}$ (baseline membrane potential) to -54 $\mathrm{mV}$, the firing rate was $\sim 7 \mathrm{~Hz}$. Hyperpolarizing to $-72 \mathrm{mV}$ reduced the rate to $\sim 5 \mathrm{~Hz}$, while at $-86 \mathrm{mV}$ the axon spiked

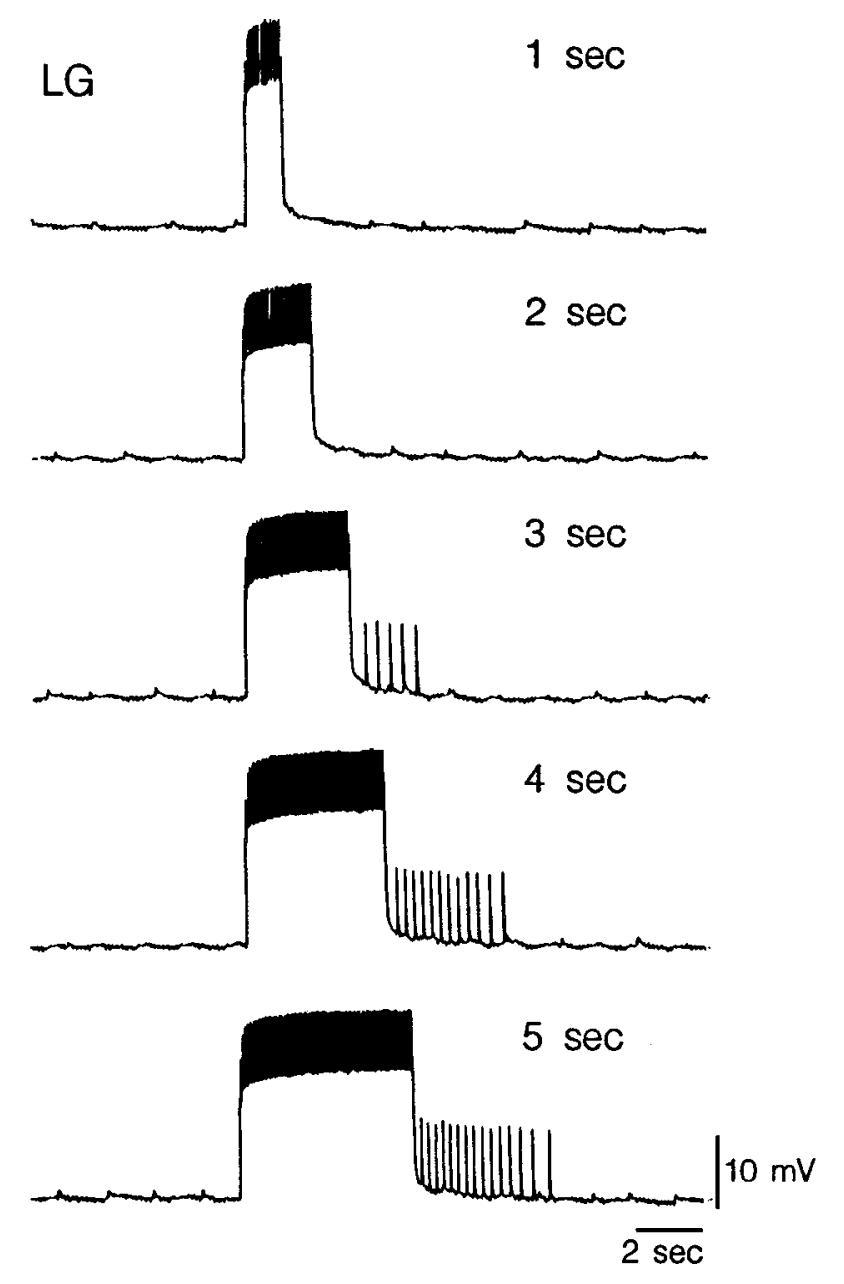

Figure 6. Expression of axonal spike initiation zone is dependent on the duration of the depolarization. LG was impaled with two electrodes, and $10^{-6} \mathrm{M}$ 5-HT was superfused over the motor nerves. LG was depolarized from $-53 \mathrm{mV}$ to $-30 \mathrm{mV}$ for varying amounts of time. Only when depolarized for $3 \mathrm{sec}$ or longer is the peripheral spike initiation zone triggered.

at $\sim 4 \mathrm{~Hz}$. When the neurite was hyperpolarized to $-95 \mathrm{mV}$, the axonal spikes ceased.

\section{Central effects}

The action potentials generated in the axon do not ordinarily evoke PSPs in neurons that are postsynaptic to the LG neuron, although they do evoke EJPs in the muscles innervated by LG. Interneuron 1 (INT 1) receives a large-amplitude IPSP from the LG neuron. Figure 8 demonstrates that the orthodromic action potentials evoke large IPSPs in INT 1 (which inhibit its firing) as well as summated EJPs in the gm6 muscle. Although the antidromic spikes produce EJPs in the gm6 muscle, they do not evoke IPSPs in INT 1. This is seen clearly in Figure 8, $C$ and $D$, which shows three triggered oscilloscope sweeps for both the orthodromic and antidromic action potentials. The orthodromic action potentials (Fig. 8C) evoked an $8 \mathrm{mV}$ IPSP in INT 1 , with the appropriate conduction and synaptic delay of $\sim 5$ msec and a corresponding time-locked EJP onto the gm6 muscle. The orthodromic action potential was generated in the ganglion between the soma and the dvn electrode; it propagated to the synaptic terminals to inhibit INT 1 and to the gm6 muscle, where it produced a discrete EJP. In contrast, the antidromic 

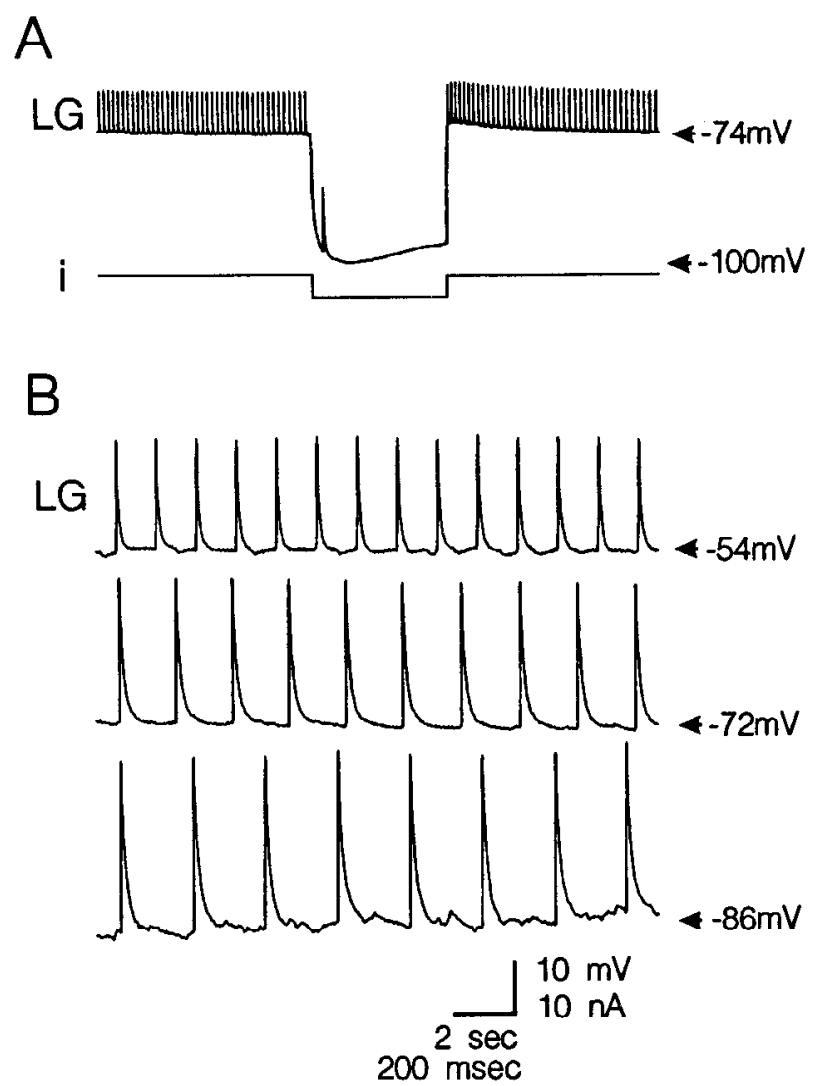

Figure 7. Current injected into the soma controls the peripheral spike initiation zone. $A$, Superfusion of $10^{-6} \mathrm{M}$ 5-HT on the motor nerves produced long-duration discharge for several minutes. Hyperpolarization of the soma from $-74 \mathrm{mV}$ (resting potential) to $-100 \mathrm{mV}$ can reach peripheral spike initiation zone and suppress action potentials. $i$, current monitor. $B$, In a different animal in $5 \times 10^{-6}$ M 5-HT, current injected into the soma while recording from the major neurite in the neuropil shows that the spike frequency decreases from $7 \mathrm{~Hz}$ at -54 $\mathrm{mV}$ to $4 \mathrm{~Hz}$ at $-86 \mathrm{mV}$. At $-95 \mathrm{mV}$ all peripheral spiking ceases. Vertical bar, $10 \mathrm{mV}$ for intracellular recording; $10 \mathrm{nA}$ for current monitor. Horizontal bar, $2 \mathrm{sec}$ for $A ; 200 \mathrm{mscc}$ for $B$.

action potential (Fig. 8D) was generated between the dvn and lvn electrodes (note the time interval between the dvn and lvn in $C$ and $D$ has changed). The spike traveled antidromically toward the dvn electrode and toward the soma, but does not elicit an IPSP in INT 1.

Since the antidromic action potentials usually follow highfrequency discharges of orthodromic activity, one possible explanation for the failure of the antidromic action potentials to evoke IPSPs is synaptic fatigue. However, the experiment shown in Figure 9 argues that this is not the case. After a 5 sec depolarization in the presence of $10^{-7} \mathrm{M} \mathrm{5-HT,} \mathrm{10-15} \mathrm{antidromic}$ spikes were seen in the LG neuron, which did not elicit IPSPs in INT 1 (Fig. 9A). In contrast, when the LG was depolarized for $5 \mathrm{sec}$ in normal saline (Fig. 9B) and then the current was reduced to a level that evoked orthodromic action potentials of the same number and frequency as the antidromic action potentials in Figure $9 A$, the LG did evoke large IPSPs in INT 1 (Fig. 9B). Thus, the inability of the low-frequency antidromic action potentials in LG to inhibit postsynaptic neurons is not a consequence of synaptic fatigue.

The above experiment demonstrates that the antidromic action potentials do not ordinarily evoke transmitter release. In
Figure 9, the postburst orthodromic action potentials are firing from a more depolarized membrane potential than the postburst antidromic action potentials. This suggested that the failure of the antidromic action potentials to evoke IPSPs may be because the voltage transient they produce in the neuropil from a hyperpolarizcd membranc potential docs not depolarize the cell adequately. Figure 10 demonstrates that this is the case. In this experiment, the LG soma membrane potential was changed and antidromic action potentials were evoked by nerve stimulation. When antidromic action potentials decremented into the neuropil without a baseline depolarization, no PSPs were evoked. However, as the baseline membrane potential in the LG was depolarized, antidromic action potentials evoked progressively larger IPSPs in INT 1 (Fig. 10A). The plot of the IPSP amplitude as function of the LG membrane potential (Fig. 10B) shows clearly that antidromic action potentials occurring during hyperpolarized interburst intervals (Figs. 2, 3, 8, 9) fail to evoke transmitter release because the $L G$ is insufficiently depolarized.

\section{Peripheral effects}

What are the behavioral ramifications of the peripheral spikes on the movement of the gastric mill? Experiments were performed to determine the effects of the train of 4-6 Hz peripherally generated action potentials on the contraction of the gastric muscles. The STG was bathed in TTX to eliminate action potentials generated in the ganglion, and the dvn was stimulated to mimic the firing pattern seen in Figure $2 B$. The membrane potential and the movement of the gm $5 \mathrm{~b}$ muscle were recorded (Fig. 11 $A$ ). High-frequency stimulation followed by low-frequency stimulation of the nerve caused an initial strong contraction, which was sustained during the low-frequency stimulation (Fig. $11 \mathrm{~B}$ ). The high-frequency stimulation alone produced the same initial contraction as that shown previously (Fig. 11C). However, the low-frequency stimulation alone produced a very weak contraction that was much smaller than the sustained component evoked by low-frequency firing in Figure $11 B$.

The three muscle groups innervated by the LG neuron, gm 8 , gm6, and gm $5 b$, respond differently to this stimulation paradigm. The most lateral of the three, gm $5 \mathrm{~b}$, is the only muscle that shows prolonged contraction due to the low-frequency late action potentials (Fig. 12A). The contractions in muscles gm 8 and gm6, which are more medial, are not prolonged by the lowfrequency burst (Fig. 12B,C). Thus, the axonal spikes prolong the contraction of the gm $5 \mathrm{~b}$ muscle bundle while doing little to the other muscles innervated by the LG neuron.

\section{Discussion}

In this article we show that the LG neuron can initiate spikes at a central site, close to the cell body, and at one or more peripheral sites along the axon, at considerable distance from the cell body. Although we have been calling these sites "peripheral," because they are not in the ganglion, it is important to note that these sites are on axons and several centimeters away from the nerve terminals and associated muscles. Spike initiation at the peripheral zones is easily detected in intracellular recordings from the soma because the peripherally initiated spikes propagate antidromically toward the soma and have different waveforms and durations than do the action potentials that are generated close to the soma.

Peripheral spike initiation occurs spontaneously in combined preparations in which the gastric mill and pyloric chamber mus- 
A

B

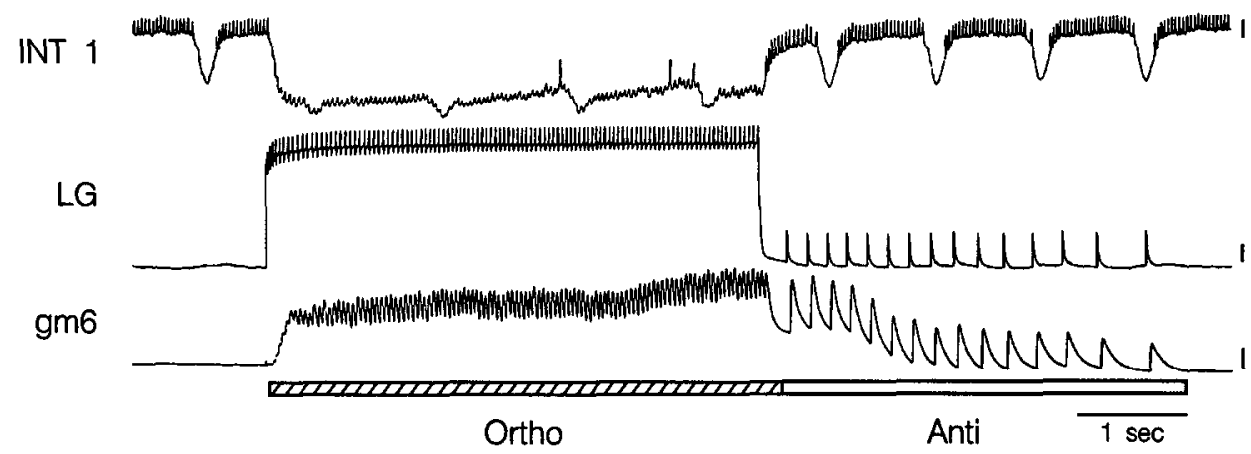

C
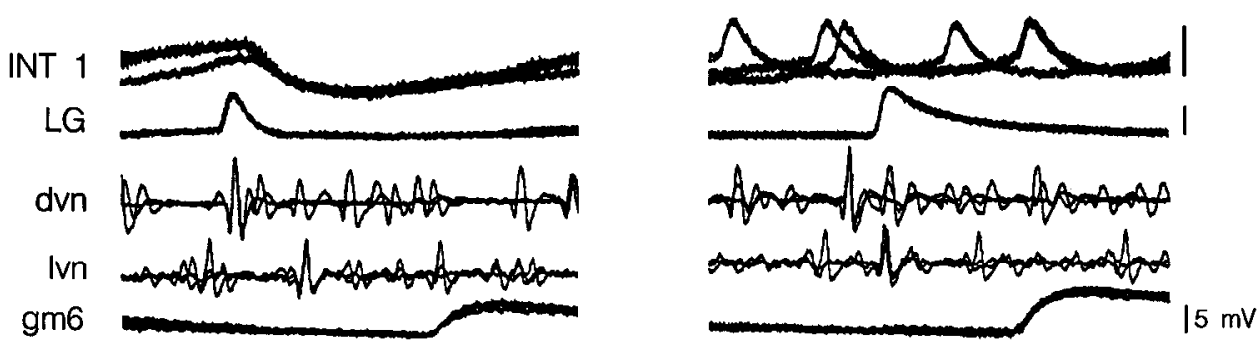

$\overline{20 \mathrm{msec}}$
Figure 8. Peripheral spikes do not have central effects. $A$, Recording configuration with a sucrose block on stn, two electrodes in LG, one electrode in INT 1 , one electrode in the gm 6 muscle, and $10^{-7} \mathrm{M} 5$-HT in the bath. $B$, Depolarizing $L G$ produces orthodromic action potentials (hatched bars) that elicit IPSPs in INT 1 and EJPs in the muscle. Antidromic spikes (open bars) do not elicit IPSPs in postsynaptic neurons in the ganglion but still elicit EJPs in the muscle. $C$, Three superimposed sweeps triggered on orthodromic LG spike in dvn during a lower-frequency plateau. Action potentials originate in the ganglion and propagate toward muscles. $D$, Three superimposed sweeps triggered on antidromic LG spike in dvn. Spikes originate between dvn and lvn and propagate toward muscles and ganglion. Antidromic spikes do not cause IPSPs in INT 1. Most hyperpolarized membrane potential: INT $1,-30 \mathrm{mV}$; LG, $-53 \mathrm{mV} ; \mathrm{gm} 6,-53 \mathrm{mV}$.

A
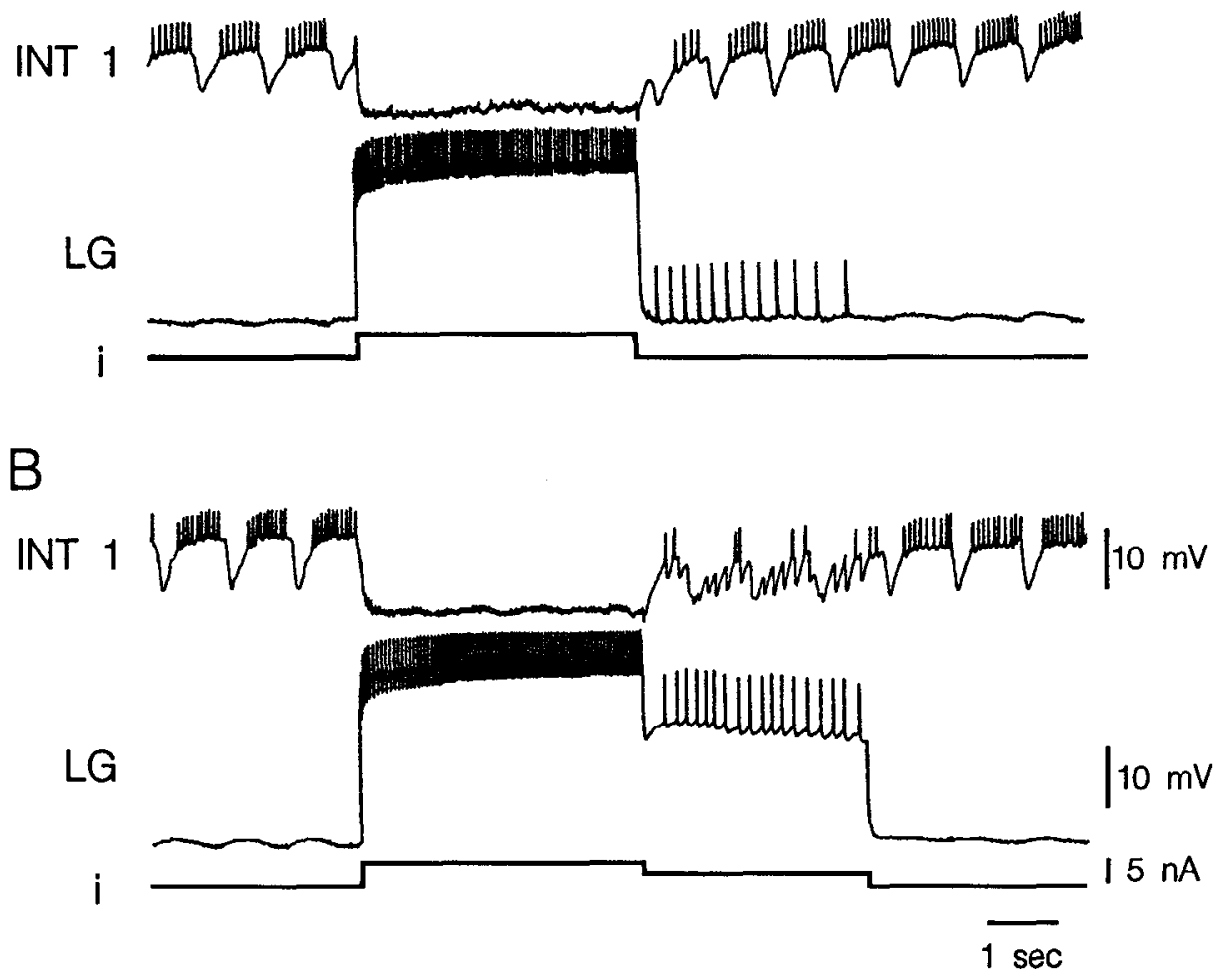

Figure 9. Inability of antidromic spikes to inhibit INT 1 is not due to synaptic fatigue. $A, \mathrm{LG}$ is depolarized for $5 \mathrm{sec}$ in $10^{-7} \mathrm{M} 5-\mathrm{HT}$. Orthodromic spikes inhibit INT 1, but antidromic spikes do not. $B$, In control saline $\mathrm{LG}$ is depolarized as in $A$ and then brought to a lower potential so that orthodromic spikes are produced at the same frequency as antidromic spikes. These lowfrequency orthodromic spikes inhibit INT 1. Most hyperpolarized potentials: INT $1,-40 \mathrm{mV}$; LG, $-68 \mathrm{mV}$. 

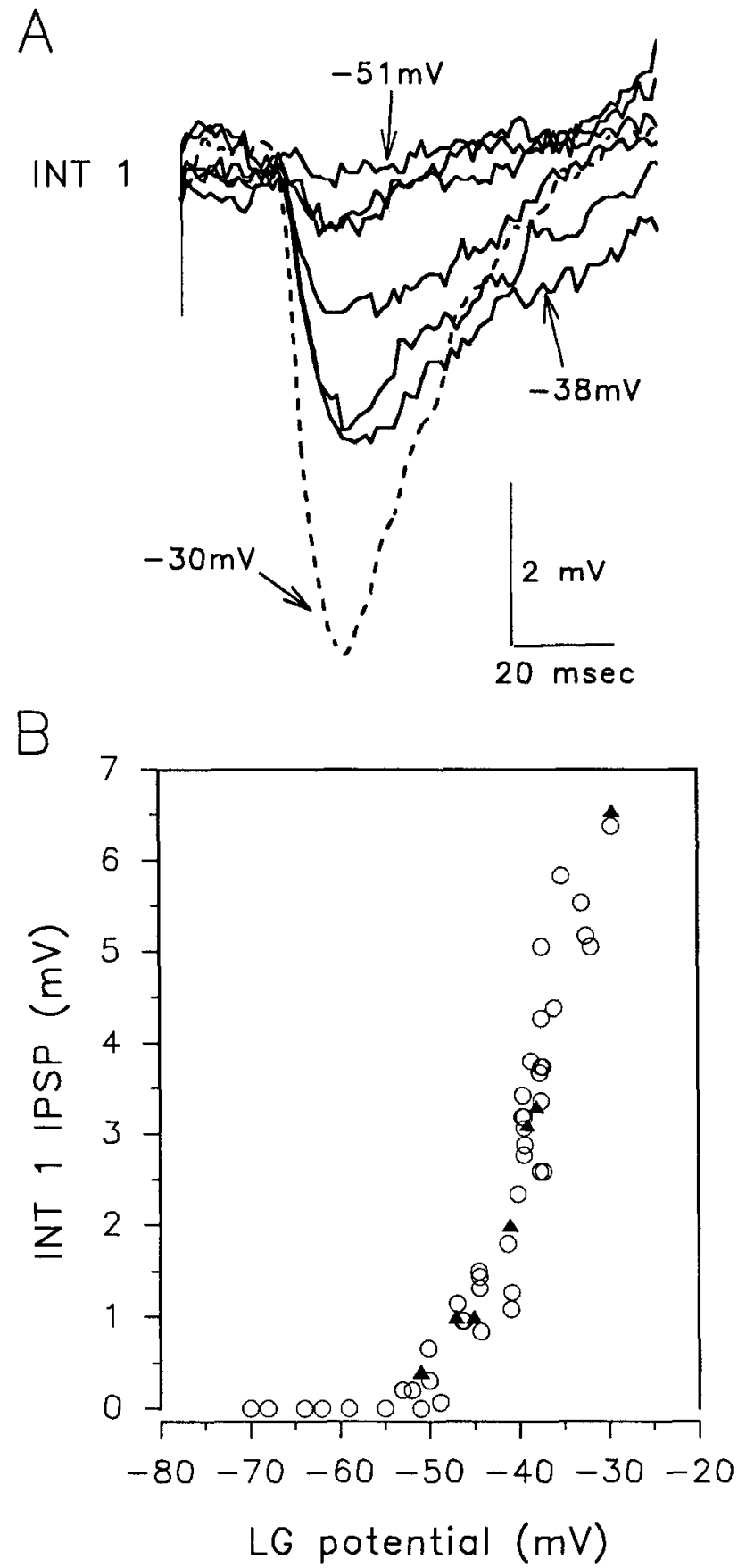

Figure 10. Membrane potential of LG determines the amplitude of INT 1 IPSP. $A$, Six superimposed sweeps of INT 1 IPSPS as LG is depolarized from $-70 \mathrm{mV}$ to $38 \mathrm{mV}$ while the LG nerve is stimulated at $2 \mathrm{~Hz}$. The broken line is from an orthodromic spike at $-30 \mathrm{mV}$. $B$, Plot of antidromically evoked IPSPs in INT 1 as LG is depolarized (open circles). The solid triangles are the seven IPSPs from $A$. The point at $-30 \mathrm{mV}$ was from a spontaneously occurring orthodromic spike.

cles are actively contracting. The presence of active muscles imparts to the LG axon the ability to generate action potentials $1-2 \mathrm{~cm}$ from the soma and neuropil, where action potential initiation usually occurs. The experimental paradigm we used to investigate the peripheral spike initiation zone focuses on only one initiation zone. However, in some experiments, two zones were observed (one on each lvn).
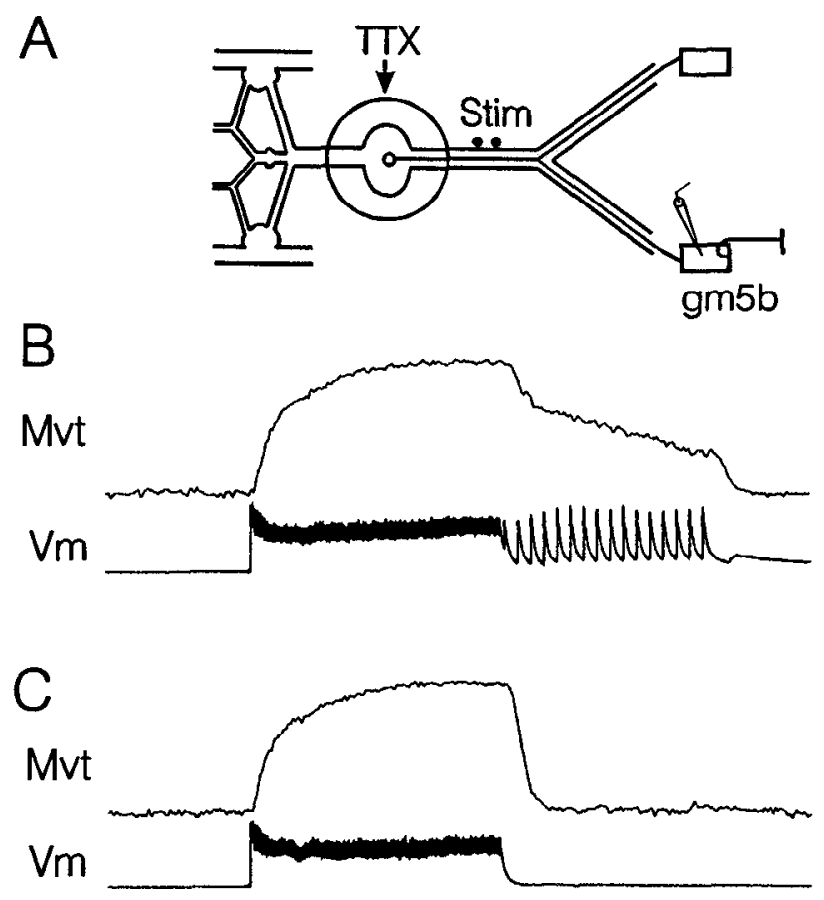

D

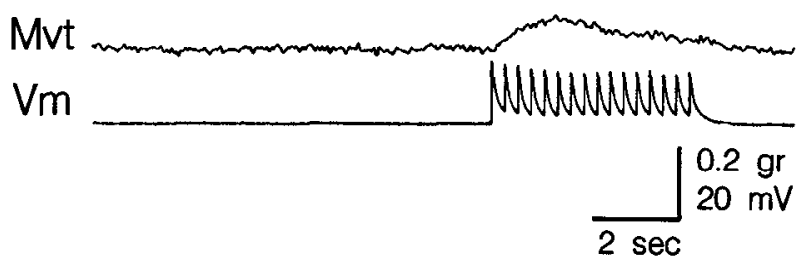

Figure 11. The peripheral spike initiation zone has behavioral consequences. $A, \mathrm{STG}$ is bathed in TTX while the dvn is stimulated via extracellular electrodes. Stimulation is $20 \mathrm{~Hz}$ for the first $5 \mathrm{sec}$ followed by $4 \mathrm{~Hz}$ for $5 \mathrm{sec}$. A force/movement transducer was attached to the muscle bundle (hook), and an intracellular electrode recorded EJPs from a muscle fiber. $B$. With stimulation paradigm above, movement of $\mathrm{gm} 5 \mathrm{~b}$ muscle is prolonged due to the extra low-frequency stimulation. $C, A$ $5 \mathrm{sec}, 20 \mathrm{IIz}$ stimulation causes a strong contraction that rclaxes quickly after stimulation. $D$, Five seconds of low-frequency stimulation cause only a slight movement of muscle (resting potential, $-59 \mathrm{mV}$ ).

What is the contribution provided by the contracting gastric mill muscles? One possibility is that muscle movement activates sensory neurons that are responsible for the induction of the peripheral spike initiation zone. This appears plausible because there are two pairs of 5-HT-immunoreactive sensory neurons in the gastric mill motor nerves (Beltz et al., 1984; Katz et al., 1989). These sensory neurons respond to contractions of the gastric mill complex and evoke actions similar to those of bathapplied 5-HT on the motor patterns produced by the STG (Katz and Harris-Warrick, 1990). Therefore, it is possible that the role of the muscles in peripheral spike initiation is mediated via these sensory receptors. However, one must keep in mind that there may be additional as yet unidentified sensory fibers in the motor nerves that may also be responsible for this phenomenon (see Dando and Maynard, 1974).

In this article, we used 5-HT to evoke antidromic action potentials in preparations in which the muscles had been removed. Recent experiments have shown the presence of 5-HTlike-immunoreactive varicosities in the region of the nerve where 
we applied 5-HT (V. Kilman and E. Marder, unpublished observations). These results argue that $5-\mathrm{HT}$, released either from the GPR neurons or from other fibers, may be released from a neurosecretory structure in the nerve in the general area that we found to be 5-HT sensitive.

Although the action potentials generated at the peripheral spike initiation can be observed in the soma of the LG neuron, these action potentials do not routinely evoke IPSPs in neurons postsynaptic to the LG. Mulloney and Selverston (1972) observed in the STG of Panulirus interruptus that antidromic action potentials failed to evoke PSPs in follower neurons. This early study was important in establishing that antidromic action potentials could not be reliably used to study the synaptic connections among neurons. Mulloney and Selverston (1972) concluded that the antidromic action potentials were blocked as they entered the ganglion and passed the minor neurites that project to the synaptic terminals. Maynard and Walton (1975) noted that presynaptic depolarization influenced transmitter release in stomatogastric neurons, suggested several mechanisms for this, but were unable to come up with a satisfactory explanation for their results. L. F. Abbott, E. Marder, and J. M. Weimann (unpublished observations) have now constructed a compartmental model of the LG neuron that reproduces the experimental data in this article. This model shows that the level of depolarization upon which the antidromic and orthodromic action potentials ride is sufficient to predict their ability to evoke transmitter release, and that more complicated explanations are not needed.

The relationship of transmitter release to presynaptic level of depolarization shown in Figure 10 is markedly similar to that reported in leech neurons (Nicholls and Wallace, 1978a,b). In the leech, prolonged depolarizations led to increases in transmitter as the presynaptic neuron was held at a constant level of depolarization, suggesting that prolonged $\mathrm{Ca}^{2+}$ influx might enhance the transmitter output. It would be interesting to determine if the time course of depolarization that occurs during rhythmic activity of the stomatogastric networks is able to give rise to similar modulation of transmitter release.

Under the conditions of these experiments, the frequency of the spikes initiated peripherally was lower than those initiated during strong somatic depolarization. Interestingly, even the low-frequency trains of extra spikes produced significant prolongation of tension in one of the muscles innervated by the LG neuron, gm5b. In the intact animal, peripherally initiated spikes may produce muscle activation in only the gm5b muscle. Alternatively, under more intact conditions, the other muscles might also show prolonged contractions caused by peripherally activated spikes.

The position of the gm $5 \mathrm{~b}$ muscle in the gastric mill complex would cause the lateral teeth to move forward during the retraction phase of the lateral teeth. Based on work in the intact $\mathrm{crab}$, when the inferior cardiac neuron, which innervates gm5a, produces a long plateau, the lateral teeth are launched forward (Heinzel and Weimann, 1990). Thus, the peripheral spikes may produce a forward movement of the lateral teeth as the teeth are being retracted. This would lead to a backward bite of the lateral teeth that may be used to clear the gastric mill.

\section{Nerve chemosensitivity}

In many of the experiments described in this article (Figs. 59), we superfused 5-HT over a region of the motor nerves containing the axon of the LG neuron. The axon itself may have
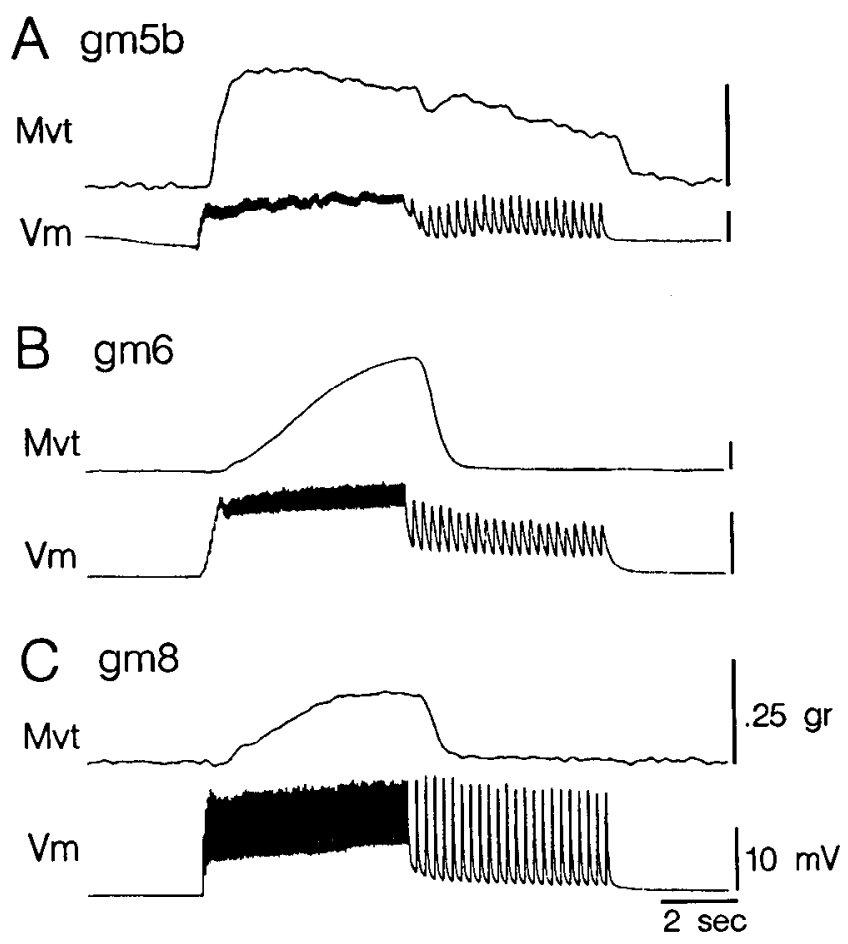

Figure 12. Only one of the three muscles innervated by LG shows potentiation (same stimulation paradigm as in Fig. 11). A, Simultaneous movement and intracellular recordings of gm5b muscle showing the sustained contraction due to low-frequency stimulation. Large movements can be seen in gm $6(B)$ and $g m 8(C)$ muscles due to high-frequency stimulation; however, these muscles do not show the sustained phase duc to low-frequency stimulation (resting potential: $\mathrm{gm} 5 \mathrm{~b},-62 \mathrm{mV}$; gm6, $-80 \mathrm{mV} ; \mathrm{gm} 8,-60 \mathrm{mV}$ ).

5-HT receptors, and locally or hormonally released 5-HT may trigger the peripheral spike initiation zone. Our experiments, however, do not demonstrate that the 5-HT receptors are on the axons themselves, because we cannot rule out the possibility that glial cells ensheathing the $L G$ and other axons are the 5$\mathrm{HT}$-sensitive cells and that these cells in turn influence the activity of the LG axons. Given the size of these structures, electron microscopic localization of the 5-HT receptors would be needed to determine unequivocally whether the 5-HT receptors are on the axon. There is a large and growing body of literature that demonstrates that glial cells show receptors for numerous neurotransmitters (Villegas, 1975; Bowman and Kimelberg, 1984; Trimmer et al., 1984; MacVicar et al., 1989), although the mechanisms by which these glial receptors might modify neuronal activity remain obscure. In a recent report, Alford et al. (1991) describe effects of GABA on lamprey spinal cord axons. As with our experiments, it is possible that the lamprey axon agonist responses are glial mediated. Alternatively, transmitter responses on axonal membranes may be a widespread phenomenon.

\section{Mechanism of peripheral spike initiation}

It is intercsting to speculate on the possible mechanisms underlying the initiation of spikes at or near the 5-HT-sensitive region of the nerve. One possibility is that 5-HT (acting either indirectly on glial cells or directly on the LG axon) induces the expression of a slow, voltage-dependent conductance such as an inward $\mathrm{Ca}^{2+}$ current or a $\mathrm{Ca}^{2+}$-dependent inward current. Assuming that the induction of this conductance is a graded func- 
tion of 5-HT concentration, it is easy to explain how high concentrations of 5-HT could produce continuous firing while lower concentrations would require somatic depolarizations of durations that vary according to the concentration of 5-HT.

Axons are usually thought to be simple conduits from an integration site (in this case close to the neuropil) to an effector site (e.g., muscle). Our results now force us to include the possibility that local axonal integration sites can participate in shaping the patterns of activity produced by a neuron. Neurons that can initiate action potentials at multiple locations may perform different behaviorally relevant outputs according to which spike initiation zones are activated by inputs to the neuron. By analogy with computer science terminology, one might argue that each spike initiation zone can be thought of as a site of information processing or a node, and that these can operate independently or in coordination. Three possible modes are evident in the LG motor neuron. First, when the peripheral zones are silent, centrally generated spikes reach the muscles and postsynaptic neurons. Second, when the peripheral zones are activated, centrally generated spikes reach all targets but peripheral spikes only reach the muscles. Third, if the membrane potential of the LG neuron is depolarized during the burst of antidromic action potentials by either synaptic or endogenous conductances, the peripheral spikes will invade the neuropil and elicit PSPs on follower neurons. This adds even more richness to the computational power of this neuron. Only in the last case will the peripherally initiated action potentials participate in the pattern-generating circuit, although in all cases movements will be influenced by the peripherally generated spikes.

\section{References}

Alford S, Christenson J, Grillner S (1991) Presynaptic GABA and $\mathrm{GABA}_{\mathrm{B}}$ receptor-mediated phasic modulation in axons of spinal motor interneurons. Eur J Neurosci 3:107-117.

Beltz B, Eisen JS, Flamm R, Harris-Warrick RM, Hooper SL, Marder E (1984) Serotonin innervation and modulation of the stomatogastric ganglion of three decapod crustaceans Panulirus interruptus, Homarus americanus, and Cancer irroratus. J Exp Biol 109:35-54.

Bowman CL, Kimelberg HK (1984) Excitatory amino acids directly depolarize rat brain astrocytes in primary culture. Nature 311:656659.

Calabrese RL (1980) Control of multiple impulse-initiation sites in a leech interneuron. J Neurophysiol 44:878-896.

Connor JA, Walter D, McKinnon R (1977) Neural repetitive firing: modifications of the Hodgkin-Huxley axon suggested by experiments from crustacean axons. Biophys J 18:81-102.

Dando MR, Maynard DM (1974) The sensory innervation of the foregut of Panulirus argus (Decapoda Crustacea). Mar Behav Physiol 2:283-305.

Dickinson PS, Nagy F, Moulins M (1981) Interganglionic communication by spiking and nonspiking fibers in same neuron. $J$ Neurophysiol 45:1125-1138.

Dudel J (1965) Facilitory effects of 5-hydroxy-tryptamine on the crayfish neuromuscular junction. Arch Exp Pathol Pharmakol 249:515528 .

Golowasch J, Marder E (1992) Ionic currents of the lateral pyloric neuron of the stomatogastric ganglion of the crab. J Neurophysiol 67: 318-331.

Grundfest H, Reuben JP (1961) Neuromuscular synaptic activity in lobster. In: Nervous inhibition (Florey E, ed), pp 92-104. New York: Pergamon.
Heinzel HG, Weimann JM (1990) Combined endoscopic and electrophysiological recordings of multiple STG rhythms in intact crabs, Cancer pagurus. Soc Neurosci Abstr 16:725.

Hodgkin AL, Huxley AF (1952) A quantitative description of membrane current and its application to conduction and excitation in nerve. J Physiol (Lond) 117:500-544.

Hooper SL, O'Neil MB, Wagner R, Ewer J, Golowasch J, Marder E (1986) The innervation of the pyloric region of the crab, Cancer borealis: homologous muscles in decapod species are differently innervated. J Comp Physiol [A] 159:227-240.

Katz PS, Harris-Warrick RM (1990) Neuromodulation of the crab pyloric central pattern generator by serotonergic/cholinergic proprioceptive afferents. J Neurosci 10:1495-1512.

Katz PS, Eigg MH, Harris-Warrick RM (1989) Serotonergic/cholinergic muscle receptor cells in the crab stomatogastric nervous system. I. Identification and characterization of the gastropyloric receptor cells. J Neurophysiol 62:558-570.

MacVicar BA, Tse FWY, Crichton SA, Kettenmann H (1989) GABAactivated $\mathrm{Cl}^{-}$channels in astrocytes of hippocampal slices. J Neurosci 9:3577-3583

Maranto AR, Calabrese RL (1984) Neural control of the hearts in the leech, Hirudo medicinalis. II. Myogenic activity and its control by heart motor neurons. J Comp Physiol [A] 154:381-391.

Maynard DM, Walton KD (1975) Effects of maintained depolarization of presynaptic neurons on inhibitory transmission in lobster neuropil. J Comp Physiol 97:215-243.

Meyrand P, Marder E (1991) Matching neural and muscle oscillators: control by FMRFamide-like peptides. J Neurosci 11:1150-1161.

Mulloney B, Selverston Al (1972) Antidromic action potentials fail to demonstrate known interactions between neurons. Science 177: $69-72$.

Nagy F, Dickinson PS, Moulins M (1981) Rhythmical synaptic control of axonal conduction in a lobster motor neuron. J Neurophysiol 45 : 1109-1124.

Nicholls J, Wallace BG (1978a) Modulation of transmission at an inhibitory synapse in the central nervous system of the leech. J Physiol (Lond) 281:157-170.

Nicholls J, Wallace BG (1978b) Quantal analysis of transmitter release at an inhibitory synapse in the central nervous system of the leech. J Physiol (Lond) 281:171-185.

Selverston AI, Moulins M (1987) The crustacean stomatogastric system. Berlin: Springer.

Smith TG Jr, Futamachi K, Ehrenstein G (1982) Site of action potential generation in a giant neuron of Aplysia californica. Brain Res 242:184-189.

Standaert FG (1963) Post-tetanic repetitive activity in the cat soleus nerve: its origin, course, and mechanism of generation. J Gen Physiol 47:53-70.

Standaert FG (1964) The mechanisms of post-tetanic potentiation in cat soleus and gastrocnemius muscles. J Gen Physiol 47:987-1001.

Tauc L (1962) Site of origin and propagation of spike in the giant neuron of Aplysia. J Gen Physiol 45:1077-1097.

Trimmer PA, Evans T, Smith MM, Harden TK, McCarthy KD (1984) Combination of immunocytochemistry and radioligand receptor assay to identify $\beta$-adrenergic receptor subtypes on astroglia in vitro. $\mathrm{J}$ Neurosci 4:1598-1606.

Vedel JP, Moulins M (1978) A motor neuron involved in two centrally generated motor patterns by means of two different spike initiation sites. Brain Res 138:347-352.

Villegas J (1975) Characterization of acetylcholine receptors in the Schwann cell membrane of the squid nerve fibre. J Physiol (Lond) 249:679-689.

Weimann JM, Meyrand P, Marder E (1991) Neurons that form multiple pattern generators: identification and multiple activity patterns of gastric/pyloric neurons in the crab stomatogastric system. J Neurophysiol 65:111-122. 